Earth Common Journal Regular Issue

Everyday Activism

MacEwan University

Volume 4, Number 1, September 2014

\title{
Opportunities and Challenges of Allocation of Alternative Energy Resources in Japan
}

\author{
Karin Snyder*
}

MacEwan University, Canada

\begin{abstract}
In the case of Japan, which lacks any significant fossil fuel reserves (Gasparatos \& Gadda, 2009, pp. 4038-4048) some alternative forms of energy production have been implemented. Japan has implemented alternative energy options such as nuclear power, photovoltaic power, hydroelectric power, and other various energy alternatives and renewable resources. These alternatives have the potential to lessen climate change. Japan is becoming an example of the economic and environmental outcomes associated with alternative energy sources. Following the Fukushima disaster, the Japanese government addressed the possibility of removing nuclear power from the energy mix entirely by 2040 (Hong et al., 2013, pp. 418-424). In May of 2012, a governmental advisory board announced its plans to replace nuclear power with a combination of renewable sources and imported fossil fuels by 2030 (Hong et al., pp. 2013, 418-424). Japan intends to supply ten percent of the country's primary energy using renewable resources by 2020, under the Strategic Energy Plan of Japan (Japan Energy Report, 2013, pp. 1-31). As reported by the Japan Forum on International Relations in 2006, increased energy demands in Asia, accompanied with pressure to reduce carbon
\end{abstract}


emissions, has created uncertainty surrounding Japan's energy security since it has a large reliance on imported fossil fuels (Nasu \& Faunce, 2013, pp. 68-74). The major goals of energy policy in Japan are energy security, economic development and environmental sustainability. To reach these goals, feed-in tariffs were approved by the Japanese government in the summer of 2012, in order to incentivize the use of renewable resources, especially photovoltaic power, and accelerate investment in renewable energy technologies (Frishberg, 2013, pp. 5-6). Since implementing these tariffs, Japan's supply of solar generated power has grown by forty percent (Frishberg, 2013, pp. 5-6). There are many criteria that need to be met for efficient and useable sustainable energy technologies, such as accessibility to remote locales, user friendliness, adaptability to local conditions, efficiency and reliability (Balachandra et al., 2010, pp. 1842-1851). This criterion can be difficult to attain for large, growing populations.

\section{Introduction}

With the end of World War II in 1945, the world saw a dramatic change in the way energy resources were utilized. Oil and petroleum became the dominant sources, while use of coal became less prominent (Podobnik, 1999, pp. 155-172). The shift towards oil and petroleum happened quickly, and is an example of how global trends in use of resources can be susceptible to significant change. Burning fossil fuels releases greenhouse gases into the atmosphere, which absorb radiation from the earth more so than radiation from the sun, and build up in the atmosphere creating a warming effect (Ramasesha, 2013, pp. 756-770). According to a study done by the United Nation's Intergovernmental Panel on Climate Change, greenhouse gas emissions are expected to raise global temperatures by two to six degrees Fahrenheit by the end of the next century (Podobnik, 1999, pp. 155-172). Currently, the environmental issue of global warming is becoming more prevalent in the media, with many environmental organizations backing the idea that humankind's recent exploitation of the environment regarding energy resource development is a considerable factor. Japan has taken a unique approach to provide energy in the present economic and environmental climate.

In Japan, the development of nuclear technologies meant the revival of the economy, damaged by the events of World War II, through the creation of jobs and new infrastructure (Shadrina, 2012, pp. 94-136). In the 1950s and 1960s, Japan experienced a drastic economic rise which resulted in a considerable increase of environmental pollution (Kanada, Fujita \& Ohnishi, 2013, pp. 92-101). Currently Japan, along with 
China and India, emit the most greenhouse gases in Asia and are projected to contribute thirty-five percent of the world's greenhouse gas emissions by 2050 (Saveyn, Paroussos \& Ciscar, 2012, pp. S451-S458). Japan, like most other developed countries, still has a lot of work to be done in the implementation of cleaner technologies.

In countries where oil and gas resources are plentiful, they are being developed to a great extent because of the economic benefits that can be gained. In the case of Japan, which lacks any significant fossil fuel reserves (Gasparatos \& Gadda, 2009, pp. 40384048), some alternative forms of energy production have been implemented. Japan is the fifth largest consumer of energy and the third largest producer and consumer of electricity in the world (Gasparatos \& Gadda, 2009, pp. 4038-4048). Because of this demand for energy and energy security, Japan has implemented alternative energy options such as nuclear power, photovoltaic power, hydroelectric power, and other various energy alternatives and renewable resources. Sustainable energy technologies are expected to act as a factor to help mitigate climate change issues (Balachandra et al., 2010, pp. 1842-1851). Although sustainable energy technologies in Japan may only be under consideration by the government due to lack of available fossil fuels, Japan is becoming an example of the economic and environmental outcomes associated with alternative energy sources. While Japan's economy is not aided much by production of energy resources, specifically oil and gas, it presently has energy consuming industries, such as steel and chemical companies that are economic boosters (Mori, 1987, pp. 207-214). Thus, Japan is in an intriguing position in which the use of alternative technologies can be economically beneficial.

\section{Present and Future Energy Mixes}

As reported by the International Energy Agency, imported energy resources from other countries accounts for ninety-five percent of Japan's domestic energy consumption (Hong, Bradshaw \& Brook 2013, pp. 418-424). Currently, eighty-one percent of this comes from imported fossil fuels (Nasu \& Faunce, 2013, pp. 68-74). In 2010, thirteen percent of Japan's consumed energy, and twenty-seven percent of the country's generated energy came from nuclear power, making Japan the third largest producer of nuclear power in the world (Nesheiwat \& Cross, 2013, pp. 509-519). However, in March of 2011, an earthquake and a resulting tsunami devastated the Fukushima nuclear power plant, resulting in a nuclear disaster that shifted public opinion away from nuclear power as a viable energy source (Shadrina, 2012, pp. 94-136). The Tokyo Electric Power Company was forced to suspend electric power from the Fukushima plant due to the damage, resulting in a loss of 9000 megawatts of power from Japan's power grid system. In response to this loss of available energy, industrial and commercial sectors had to 
reduce their power consumption during peak times by ten percent compared to the power consumption of the previous year, which they were successful in achieving (Tanaka \& Ida, 2013, pp. 296-304).

Following the Fukushima disaster, the Japanese government addressed the possibility of removing nuclear power from the energy mix entirely by 2040 (Hong et al., 2013, pp. 418-424). In May of 2012, a governmental advisory board announced its plans to replace nuclear power with a combination of renewable sources and imported fossil fuels (Hong et al., 2013, pp. 418-424). Originally, nuclear power had been a key aspect in the energy plans that Japan had made in order to reach their goals set out by the Kyoto accord. The Kyoto accord was ratified in 2002, in which Japan made a long term commitment to reduce greenhouse gas emissions by eighty percent in 2050 compared to the 1990 levels (Japan Energy Report, 2013, pp. 1-31). The Japanese government is now weighing the options as to the most beneficial energy mix for the future, aiming to implement a new mix by 2030. There are four proposed energy mixes, consisting of the following: 1)no nuclear power, 2) fifteen percent nuclear power, 3) twenty percent nuclear power, and 4) thirty-five percent nuclear power (Hong et al., 2013, pp. 418-424). Japan intends to supply ten percent of the country's primary energy using renewable resources by 2020, under the Strategic Energy Plan of Japan (Japan Energy Report, 2013, pp. 1-31). Japan is ranked as the sixth largest producer of solar power in the world (Nesheiwat \& Cross, 2013, pp. 509-519), making photovoltaic power a viable option for renewables. A global reliance on fossil fuels will create challenges for most countries to implement alternative options; however Japan has an environmental and economical motivation to do so. While moving away from nuclear power may create an increased reliance on fossil fuels, increasing efficiency of solar power may be a viable option in the future.

\section{Energy Policy}

As reported by the Japan Forum on International Relations in 2006, increased energy demands in Asia accompanied with pressure to reduce carbon emissions has created uncertainty surrounding Japan's energy security, since it has a large reliance on imported fossil fuels (Nasu \& Faunce, 2013, pp. 68-74). The major goals of energy policy in Japan are energy security, economic development and environmental sustainability. In order to attain these goals and balance Japan's responsibilities to the Kyoto Accord, two new bills were passed in 2003 (Japan Energy Report, 2013, pp. 1-31). The first bill required industrial and commercial sectors to implement an energy efficiency strategy, with the goal of reducing carbon dioxide emissions by 2.1 mega tonnes country wide. The second bill aimed to double electricity production from renewable resources, with 
the goal of reducing carbon dioxide emissions by 3.1 mega tonnes country wide. More recently, the Japanese government adopted a new energy plan, called the New Basic Energy Plan, (Duffield \& Woodall, 2011, pp. 3741-3749) which consists of five main targets. The first is to raise the counties energy independence ratio from thirty eight percent to seventy percent. An energy independence ratio relates primary energy supply produced domestically, including renewables and nuclear power, to self-developed fossil fuel supplies, which consists of imported coal, natural gas, crude oil and liquefied petroleum (Duffield \& Woodall, 2011, pp. 3741-3749). The second target is to decrease the amount of carbon dioxide being released from electricity generating power sources from thirty four percent to seventy percent. The other three targets are to halve the carbon dioxide emissions from residential sectors, maintain the energy efficiency of the industrial sector and to maintain or obtain valuable shares of energy related products or systems in global markets, thusly increasing Japan's global economic standing (Duffield \& Woodall, 2011, pp. 3741-3749). These targets will be beneficial in helping to mitigate climate change.

To reach these goals, feed-in tariffs were approved by the Japanese government in the summer of 2012, in order to incentivize the use of renewable resources, especially photovoltaic power, and accelerate investment in renewable energy technologies (Frishberg, 2013, pp. 5-6). Feed-in tariffs were first introduced in Germany, where the scheme helped to increase Germany's use of renewable sources from three percent in 1990 to twenty percent in 2011 (Tveten, Bolkesiø, Martinsen \& Hvarnes, 2013, pp. 776770). Feed-in tariffs work by granting individual households or commercial projects a fixed price on eligible renewable electricity production of which they contribute to the power grid. Any amount of energy being generated that is over the amount being used by the house or commercial building will be bought back for the price of the feed-in tariff rate (Frishberg, 2013, pp. 5-6). Feed-in tariffs provide an incentive for citizens to both install renewable energy sources and to contribute energy to the power grid that comes from a renewable source. Since implementing these tariffs, Japan's supply of solar generated power has grown by forty percent (Frishberg, 2013, pp. 5-6). Governmental energy policies in Japan take into account the benefits of the citizens, environment and local economy.

\section{Challenges Associated With Alternative Energies}

Japan is challenged by implementation of new technologies. Examples include the negative public opinion following the Fukushima nuclear power plant disaster and a lack

of available land for large scale solar projects. Japan is part of a complex geological area that is highly prone to earthquakes. The Japan Trench runs along the east coast of the 
archipelago of Japan, and the Nankai Trough and Okinawa Trough are south of the islands. The islands are bordered by the Philippine Sea Plate, Pacific, and Eurasian tectonic plates (Wakita, 2013, pp. 75-87). The seismic uncertainty that results from this geographic complexity creates many problems for nuclear power plants, since the possible radioactive dangers of a malfunction in a nuclear power plant are potentially great. Incidents that cause the meltdown of a nuclear reactor core are generally unlikely; however, the consequences of a core meltdown can cause critical damage to humans and the environment. The Atomic Energy Agency set out guidelines that necessitate two meter thick walls around the reactor core to block radiation. Should these become exposed in an accident, radioactive isotopes would be released into the environment (Danger Zone, 2013, pp. 21-23). In the late 1980s in Japan, approximately ten percent of the population was against nuclear power, and now approximately seventy percent of the public is against nuclear power following Fukushima (Shadrina, 2012, pp. 94-136). The incident at Fukushima has also influenced public opinion of nuclear power negatively on a global scale, resulting in the government of China halting all nuclear projects, and Belgium and Germany adopting nuclear phase out plans (Schneider \& Froggatt, 2012, pp. 8-22). The growing apprehension around nuclear power has led to investigation and implementation of alternative energy resource use.

Implementation of renewable resources is of great interest in Japan, specifically solar power. However, Japan has a very dense population with little excess land available for development. Large scale solar facilities are therefore not a viable option, and cooperation from individuals and businesses are necessary. Although feed-in tariffs provide some incentive to install solar panels, initial start-up costs can be a deterrent for less wealthy members of society or for those uneducated about the benefits. Since solar power systems are expensive to implement, they have a long payback time. Additionally, solar power cannot be continuous and stable due to lack of solar radiation at night and during cloudy days (Chen \& Riffat, 2011, pp. 1-13). In order for solar power to compete in the global market, generating costs must be brought down by research and development of new technologies, as current technologies do not allow for the most efficient conversion into electricity (Lee, Chun, He-Yau \& Wen, 2012, pp. 1271-1291). As technology continues to develop in the future, the use of solar power is likely to be highly beneficial in acting as a replacement for fossil fuels, especially in the absence of nuclear power due to a diminishing public opinion on nuclear power.

Eighty percent of renewable energy in the future of Japan is expected to come from individual households (Frishberg, 2013, pp. 5-6). Renewable resources not including solar power, such as wind power, hydroelectric power, geothermal power and biofuels, 
constituted approximately four percent of Japan's total energy generation in 2009, of which hydropower makes up a large portion. However, hydroelectric power demands very high start-up costs (Nesheiwat \& Cross, 2013, pp. 509-519). While Japan is now struggling to reduce greenhouse gas emissions without nuclear power, the result of this recent opposition to nuclear power could open the floor to discussions regarding new technologies that are safer and offer more energy security. Due to a lack of available fossil fuels, the future of Japanese economic growth in the energy sector will necessitate increased funding for research and development of possible alternatives that could be implemented.

\section{Global Views of Energy Resources}

Sustainable energy technologies are important to develop because they have potential to mitigate climate change (Balachandra, Kristle \& Reddy, 2010, pp. 18421851). There are many criteria that need to be met for efficient and useable sustainable energy technologies, such as accessibility to remote locales, user friendliness, adaptability to local conditions, efficiency and reliability (Balachandra et al., 2010, pp. 1842-1851). Countries that attribute large portions of their gross domestic product and gross national product on oil and petroleum will face problems in the future. Population growth and consumerist societies are increasing the need for oil and gas; a need which is outpacing availability. Known petroleum reserves in the world will likely only last for forty to sixty years, according to the World Energy Council (Podobnik, 1999, pp. 155-172). For this reason, resources such as petroleum are both economically and environmentally unsustainable. Early development of alternative technologies is important in ensuring that the future economy and environment of a country is secure. Development of alternative energy sources should be a global priority, as the present overuse of fossil fuels are resulting in global warming which poses negative consequences to the environment internationally.

In December of 2009, world leaders assembled at the United Nations Climate Change Conference in Copenhagen to discuss possible plans to reduce carbon dioxide emissions. The main agreements were that renewable energies are necessary to reduce greenhouse gas emissions and crucial for an infinite availability of electricity supply. Major concerns for selecting an appropriate alternative energy source are safety of humans and care of the environment (Lee et al., 2012, pp. 1271-1291). Global warming and diminishing fossil fuel supplies are forcing other countries, not just Japan, to reconsider the energy resources that they are consuming and developing. In the United States, coal and natural gas account for seventy percent of electricity generation. The development of new technologies is essential for energy use that moves away from fossil 
fuels (Ansolabehere \& Konisky, 2012, p. 61). In a series of public opinion surveys carried out at Harvard and MIT Universities, individuals were found to hold beliefs about fuel resources that did not accurately reflect the true benefits and harms of each energy source in both economic and environmental terms. Additionally, individuals value both the environment and affordability of fuel resources (Ansolabehere \& Konisky, 2012, p. 61). Because of the inaccurate beliefs held by individuals about energy resources, further education to individuals should be a priority, so that people may make informed decisions about what type of energy resources they would prefer to have in place. Governmental and non-governmental organizations that are concerned with climate change and its relation to fossil fuel burning would be a beneficial resource to provide accurate and non-biased information to the public on the topic of energy resources. Solar power is one of the more popular choices for alternative energy following Fukushima.

Solar power is a clean, quiet and sustainable energy source that is gaining popularity due to high potential for emissions savings (Chen \& Riffat, 2011, pp. 1-13). Photovoltaic power is expected to account for one percent of the world's electricity generation in 2030, an increase from 2009, in which it accounted for 0.1 percent of worldwide electricity generation. This growing global popularity is driven by falling costs of solar power, introduction of new technologies, interest from investors, and strong policy support such as the feed-in tariff program in Japan (Lee et al., 2012, pp. 1271-1291). Now, more than fifty nations have implemented feed-in tariff programs to promote the use of renewable resources, such as solar or other applicable options, which have had more success than tax-based incentives (Frishberg, 2013, pp. 5-6).

Discussions of alternative energy resources have been encouraged recently in Japan. While other countries have been cutting back on incentive programs, Japan has not (Frishberg, 2013, pp. 5-6), making the country an example of both the problems and opportunities that are associated with policies that explore the implementation of alternative energy sources. While the environmental positives associated with alternatives such as solar power and nuclear power are globally beneficial, public opinion must be in support of these alternatives in order for them to become viable options. While nuclear power was quite a viable alternative, the accident at Fukushima shifted the public opinion and Japanese policy makers have been pressed to explore alternatives such as solar power. Japan, like the rest of the world, must consider different options regarding energy generation and consumption for the future in order to mitigate the problems associated with energy resources such as oil and coal. While these have yet to be phased out in any country, Japan will be ahead of the competition in the future if they continue 
to explore alternative sources of energy. The increasing use of alternative energy resources in both Japan and in the rest of the world appears to be gaining popularity among the public. Development of efficient technology is globally essential in order to mitigate climate change and keep up with changing economies that will eventually feel pressure to move away from excessive use of fossil fuels. On a more individual scale, actively pressuring the governments to decrease use of petroleum products, as well as decreasing the use of these products when possible, can create a positive impact on global warming from decreased burning of fossil fuels.

* Author: Karin Snyder is in her final year of a Biological Sciences degree at MacEwan University

\section{References}

Ansolabehere, S. M., \& Konisky, D. M. (2012). The American Public's Energy Choice. Daedalus, 141(2), 61.

Balachandra, P. P., Kristle Nathan, H., \& Reddy, B. (2010) Commercialization of Sustainable Energy Technologies. Renewable Energy: An International Journal, 35(8), 1842-1851.

Chen, H., \& Riffat, S. B. (2011). Development of Photovoltaic Thermal Technology in Recent Years: A Review. International Journal of Low Carbon Technologies, 6(1), $1-13$.

Danger Zone. (2013). New Scientist 218(2919), 21-23.

Duffield, J.S., \& Woodall, B. (2011). Japan’s New Basic Energy Plan. Energy Policy, 39(6), 3741-3749.

Frishberg, M. (2013). Incentives Spark Solar Energy Boom for Japan. Research Technology Management, 56(3), 5-6.

Gasparatos, A., \& Gadda, T. (2009). Environmental Support, Energy Security and Economic Growth in Japan. Energy Policy, 37(10), 4038-4048.

Hong, S., Bradshaw, C. A., \& Brook, B.W. (2013). Evaluating Options for the Future Energy Mix of Japan after the Fukushima Nuclear Crisis. Energy Policy, 56, 418424.

Japan Energy Report. (2013). Global Energy Market Research: Japan, 1-31. 
Kanada, M., Fujita, T., Fujii, M., \& Ohnishi, S. (2013). The Long-Term Impacts of Air Pollution Control Policy: Historical Links between Municipal Actions and Industrial Energy Efficiency in Kawasaki City, Japan. Journal of Cleaner Production, 58, 92 101.

Lee, A. I., Chun Yu, L., He-Yau, K,. \& Wen Hsin, L. (2012). An Integrated Performance Evaluation Model for the Photovoltaics Industry. Energies (19961073), 5(4), 1271 1291.

Mori, Y. (1987). Progress in Research and Development on Energy in Japan. JSME International Journal, 30(260), 207-214.

Nasu, H., \& Faunce, T. (2013). Nanotechnology in Japan: A Route to Energy Security After Fukushima? Bulletin of The Atomic Scientists, 69(5), 68-74.

Nesheiwat, J., \& Cross, J. (2013). Japan's Post-Fukushima Reconstruction: A Case Study for Implementation of Sustainable Energy Technologies. Energy Policy, 60, 509519.

Podobnik, B. (1999). Toward a Sustainable Energy Regime: A Long-Wave Interpretation of Global Energy Shifts. Technological Forecasting \& Social Change: An International Journal, 62(3), 155-172.

Ramasesha, S. (2013). Challenges in the Quest for Clean Energies. Resonance: Journal of Science Education, 18(8), 756-770.

Saveyn, B., Paroussos, L., \& Ciscar, J. (2012). Economic Analysis of a Low Price Carbon Path to 2050: A Case for China, India and Japan. Energy Economics, 34, S451S458.

Schneider, M., \& Froggatt, A. (2012). 2011-2012 World Nuclear Industry Status Report. Bulletin Of The Atomic Scientists, 68(5), 8-22.

Shadrina, E. (2012). Japan's Pre and Post 3/11 Energy Policy: Distressing Lessons and Blurred Prospects. YDU Sosyal Bilimier Dergisi/NEU Journal of Social Science, 5(2), 94-136.

Tanaka, M., \& Ida, T. (2013). Voluntary Electricity Conservation of Households After the Great East Japan Earthquake: A Stated Preference Analysis. Energy Economics, 39, 296-304.

Tveten, Å., Bolkesiø, T., Martinsen, T., \& Hvarnes, H. (2013). Solar Feed-in Tariffs and the Merit Order Effect: A Study of the German Electricity Market. Energy Policy, 61, 776-770. 
Wakita, K. (2013). Geology and Tectonics of Japanese Islands: A Review - The Key to Understanding the Geology of Asia. Journal of Asian Earth Sciences, 72, 75-87. 